\title{
“MANUSCRITO DE BUENOS AIRES”, DE FRANCISCO JOSÉ VIEGAS: UMA INVESTIGAÇÃO LITERÁRIA
}

\author{
Adenize Franco \\ Aline Venturini ${ }^{* *}$
}

RESUMO: Este artigo detém-se na análise do conto "Manuscrito de Buenos Aires" (2008), de Francisco José Viegas, considerando os elementos pertencentes ao gênero policial e à ficção contemporânea que podem ser verificados na construção narrativa. A recorrência a tais traços é característica da obra de Viegas, para quem "toda literatura é policial". Nesse sentido, o conto em destaque é marcado não só por elementos do policial, tais como personagem detetivesco, o desaparecimento de um objeto (manuscrito) e a procura para desvendar o enigma, mas também por elementos que são destaque na narrativa contemporânea, como a intertextualidade e a referência à própria literatura. A narrativa sagra-se, portanto, como um elogio, especialmente, à obra de Jorge Luiz Borges e Miguel de Cervantes e a uma investigação que tem a literatura como objeto de obsessão.

PALAVRAS-CHAVE: Francisco José Viegas. Gênero policial. Narrativa contemporânea

\footnotetext{
* Docente do Departamento de Letras e do Programa de Pós Graduação em Letras da Universidade Estadual do Centro Oeste /PR (Unicentro). Doutora em Estudos Comparados de Literaturas de Língua Portuguesa (FFLCH/USP). E-mail: adenizeafranco@gmail.com

** Mestre em Literatura Brasileira e doutoranda em Literatura Espanhola, sob a orientação do professor doutor Ruben Daniel Castiglioni pela Universidade Federal do Rio Grande do Sul. Professora do Instituto Federal de Ciência e Tecnologia Sul Rio Grandense, campus Passo Fundo/RS. E-mail: alineventurini260780@gmail.com
} 


\section{Manuscrito de Buenos Aires: em busca do Quixote}

O conto "Manuscrito de Buenos Aires" integra a antologia de contos nomeada Contos Policiais, coordenada por Pedro Sena-Lino e publicada pela Porto Editora, em 2008. O livro apresenta nove contos de vários escritores portugueses contemporâneos, tais como Gonçalo Tavares, Mário Cláudio, Rui Zink, Walter Hugo Mãe, Hélia Correia, Dulce Maria Cardoso, Mafalda Ivo Cruz, Ricardo Miguel Gomes e Francisco José Viegas. Trata-se de um projeto cujos escritores detêm-se na produção de narrativas de cunho policial.

Este artigo foi escrito a quatro mãos, por isso, a razões de ser o recorte que esse artigo atende, como não poderia deixar de ser, a interesse de duas pesquisadoras, conjugando interesses teóricos. O conto de autoria de Francisco José Viegas é nosso objeto, portanto, porque de um lado o autor tem sido referencial de nossa pesquisa há algum tempo, de outro, porque se constitui como um elogio à obra de Jorge Luis Borges e de Miguel de Cervantes, atendendo, dessa forma a duas pesquisas.

Francisco José de Viegas é autor de grande produtividade e aliado à estética do gênero policial. Embora mais voltado à produção de romances, apresenta um conto no qual as várias nuances da narrativa policial podem ser observadas. Além disso, a narrativa deixa entrever a relação com a tradição da narrativa policial, especialmente se a considerarmos como um elogio ao escritor argentino Jorge Luís Borges, dada a variedade de referências que se entrecruzam, tanto com o autor quanto com a literatura latino-americana, bem como, com outros autores de romances policiais e suas produções. Vale frisar que Borges foi um dos autores dedicado a pensar a narrativa policial, desde seu prefácio à narrativa $A$ invenção de Morel (1940), de Adolfo Bioy Casares ao texto "Conto policial" (1978), ou as próprias narrativas que transgrediam, muitas vezes, as normas caracterizadoras do gênero.

Em síntese, "Manuscrito de Buenos Aires" narra a história de um professor universitário português, em licença sabática, que se encontra em Buenos Aires para uma pesquisa (na verdade o personagem considera "uma obsessão") acerca de um possível manuscrito contendo uma parte da obra Dom Quixote de La Mancha, de Miguel de Cervantes. A narrativa 
entrelaça a relação do professor inominado a Lucas Corso (personagem do romance El Club Dumas, do espanhol Arturo Pérez), "um caçador de edições raras”, ou seja, não só o conflito da narrativa se inscreve na constituição da narrativa policial quanto outros elementos que correspondem ao universo literário (personagens, obras, autores) corroboram para um universo investigativo. Ao fim e ao cabo, o manuscrito - conforme já assinalamos como possível elogio a Borges - busca inscrever-se na linha de "Pierre Menard - o autor de Quixote", cuja escrita deriva da reescritura mais do que uma existência autônoma e autêntica.

O conto "Manuscrito de Buenos Aires" pode ser compreendido como um elogio à narrativa policial e a um de seus maiores cultuadores que foi Jorge Luis Borges. O título da obra contextualiza o espaço em que a narrativa transcorre, a capital argentina e berço do escritor Borges. Antes de iniciar a narrativa, há a dedicatória do conto, indicada ao escritor espanhol Arturo Pérez-Reveré, um dos maiores escritores contemporâneos de romance policial, cuja obra El clube Dumas - levado à transposição fílmica O último portal (1999), por Roman Polanski - narra a investigação do personagem Luís Corso em busca de um manuscrito. Esta personagem, por sua vez, é incorporada ao conto de Francisco José Viegas,

Só uns meses mais tarde, num encontro sobre edição de manuscritos do século XVIII, em Salamanca, pôde conversar com Lucas Corso sobre Rodríguez Tiberi e sobre eventuais rumores acerca de Cervantes ou dos seus manuscritos. Corso era conhecido como um caçador de edições raras e, muito frequentemente, as universidades e as bibliotecas - embora desconfiassem dele e temessem ver-se associados ao espanhol - recorriam aos seus serviços, que eram bem pagos e geralmente pisavam o risco da ilegalidade. Esse conhecimento datava de há alguns anos, quando Lucas Corso rondou Lisboa no meio de uma investigação sobre um manuscrito de Dumas (VIEGAS, 2008, p.28)

O professor universitário português, protagonista do conto de Viegas, procura Corso para ajudá-lo a conhecer o autor de um artigo acadêmico em que era mencionado o Quixote de Cervantes, e La literatura que no existe, de Jorge Luís Borges. O autor de Buenos 
Aires chamava-se Rodriguez Tiberi e possuía um pretenso manuscrito apócrifo de Cervantes, não utilizado na primeira edição de Dom Quixote.

A correspondência entre o personagem Luís Corso do romance El Club Dumas, do espanhol Arturo Pérez e Lucas Corso, presente no conto "O manuscrito de Buenos Aires" constitui-se como uma investigação em torno da autoria verdadeira do manuscrito considerado uma edição rara com vistas a saber, se ele foi escrito, de fato, por Miguel de Cervantes Saavedra. A alardeada ilegalidade de Corso relaciona-se com a ideia de plágio $\mathrm{x}$ produção autêntica e também com a veracidade da voz do narrador e sua liberdade de expressão, discussão que permeia a linha narrativa do texto. O personagem se constitui em uma voz que não é totalmente confiável, instaurada por meio da investigação literária que o conto de Viegas empreende.

A comprovação da autoria e a veracidade da voz do narrador se fazem presentes tanto no Quixote de Cervantes, quanto em Pierre Menard, de Borges. Nesse sentido, o "Manuscrito de Buenos Aires" e Pierre Menard são dois textos que resultam da recepção de Viegas e de Borges em torno do Quixote. Os dois textos abordam o tema da autoria e da voz narrativa tratados por Cervantes. Pode-se assinalar que eles instauram uma cadeia de leitura, que permite narrar uma pequena fração da história da leitura de Dom Quixote de la Mancha como obra literária, dando, também, visibilidade à sua contribuição na formação da cultura ocidental.

Dessa forma, o principal mistério que move o conto é a busca pelo manuscrito e a dúvida que paira em torno dele, quando questiona se a autoria do manuscrito é ou não de Cervantes. Lucas Corso é, diante disso, personagem crucial na obra por ligar Cervantes, Jorge Luís Borges, o cego Evaristo Cárdenas, o crítico literário Rodríguez Tiberi ao protagonista, que é o professor português, cuja identidade é desconhecida. Sublinhe-se que todos eles são leitores do Quixote. 


\section{De Lucas Corso a Cervantes}

Os textos entrelaçados por Viegas, em torno do Quixote, de Cervantes em seu conto sinaliza para uma série de criações literárias, formando desse modo, uma cadeia leitora. Este elemento se constitui como uma inovação estética no que tange à metalinguagem e à reflexão literária do texto em torno de si mesmo, elemento presente no próprio Quixote. Jorge Luís Borges, Franscisco José Viegas e o personagem Evaristo Cárdenas são escritores leitores de Quixote e, de alguma forma, recriam-no em suas obras literárias e reescrevem-no, não insurgindo plágio, mas estruturando novas resignações e obras literárias. De acordo com Gadamer (1900, edição 1997, p. 19-20), esses leitores interpretam a obra literária não levando em conta somente o contexto da obra e o seu próprio, mas também as leituras anteriores feitas em torno do Quixote realizadas, tendo em vista que:

A universalidade do ponto de vista hermenêutico não tolera uma restrição, segundo meu parecer, também lá onde se trata da multiplicidade da tomada de interesses históricos, que se reúnem na ciência da história. Certamente que existem muitos modos de escrever a história e de pesquisar a história. Não se pode dizer, de modo algum, que toda tomada de interesse histórico tenha seu fundamento na realização consciente de uma reflexão histórico-efeitual. A história da tribo dos esquimós norte-americanos é com certeza completamente independente de que ela possa ter tido influências ou não na "história universal da Europa", e de quando isso possa ter ocorrido. GADAMAR, 1997, p. 19-20)

O mesmo autor destaca, ainda, a impossibilidade de negar de forma lúcida e consequente, pelo fato de a reflexão histórico-efeitual mostrar nuances de uma tarefa histórica. O retorno à história dessas tribos escritas na atualidade tenderá a significa-la como uma história ultrapassada, tendo em vista o conhecimento acumulado que possibilita novas interpretações e a busca de fontes mais adequadas. Outra questão que resulta desse retorno e contribui para uma nova interpretação é o fato de em 1960 as fontes eram lidas de modo diverso, tendo em vista os pressupostos e interesses que suscitam outras questões, distintas das que motivam a atualidade. Gadamar (1997, p. 19-20) diz também que 
Querer simplesmente substituir a grafia e a investigação histórica à competência da reflexão histórico-efeitual, significaria reduzi-la à indiferença extrema. É justamente a universalidade do problema hermenêutico que questiona retrospectivamente todas as espécies de interesse pela história, porque envolve cada vez mais naquilo que está como fundamento para a "questão histórica".

A multiplicidade de interesses históricos, a que refere Gadamer (1900), está posta no conto de Viegas (2008) no destaque dado ao fato de que tanto ele quanto Borges, Corso e Cárdenas debatem-se com o mesmo enigma, posto em Quixote: teria Cervantes suprimido partes de seu texto original, ainda não conhecidas? Dentro dessa questão primordial, um manuscrito aparece, misteriosamente, na Argentina, nas mãos de Rodríguez Tiberi, professor, também leitor de Cervantes e que se posiciona como crítico literário. Dessa posição, levanta a hipótese, em seu artigo, em torna da afirma de que "La literatura que no existe", havendo portanto, mais para se conhecer do Quixote, através de pedaços retirados da obra e que não foram publicados, em detrimento de tudo que foi, efetivamente, publicado. Assim, o mistério principal configurado na obra de Viegas é: o manuscrito portenho foi mesmo escrito por Cervantes por outro escritor, que o reescreveu e se fez passar por ele?

Viegas (2008) traz à tona a problemática em torno da veracidade da autoria, a qual é, aparentemente, solucionada por Corso no final do conto, permanecendo, entretanto, ainda envolta em mistério, resultante dos seguintes questionamentos: estaria este personagem falando a verdade? Foi Cárdenas que escreveu e observou o professor lusitano o tempo todo ou realmente era um manuscrito raro, escrito por Cervantes? Essas questões movem o protagonista em busca da resolução do mistério do manuscrito.

A discussão literária, bem como a busca pelo manuscrito, definidor do fio investigativo do conto, inicia-se com a cena em que o professor português organizava seus papéis, materiais e correspondências e depara-se com uma revista, que ele ainda não havia observado:

[...] foi então que abriu aquele exemplar de uma revista de Buenos Aires e onde descobriu o artigo sobre "La literatura que no existe". A tese do autor, um até aí ignorado Rodríguez Tiberi, mencionava 
justamente Cervantes e começava com uma citação de Jorge Luís Borges, uns versos de El otro, el mismo, o seu livro de poemas de 1964. O que lhe chamou a atenção foi esse parágrafo fatal, que copiou, traduziu e acabou por afixar no quadro de cortiça que decorava uma das paredes do gabinete: "É possível que muitos autores tenham, como Cervantes no Quijote, limitado a sua obra ao que se podia conhecer na sua edição. Não ao que foi de facto escrito. (VIEGAS, 2008, p.28)

Viegas assinala, ainda, o fato de que fragmentos desaparecidos de obras raras e de valor literário inquestionável poderiam ser destruídas caso esses manuscritos, nunca utilizados. Segundo ele, “a isso foram os autores obrigados pelos seus editores, pelo poder do Estado, da Igreja ou da sua consciência ou conveniência. O que sabemos do Quijote ou de suas primeiras edições permite apenas suposições" (idem, p. 28). Se os manuscritos tivessem sido conhecidos, a história ocidental seria distinta. Essa constatação interessou-se sobremaneira, tendo em vista as polêmicas sobre o original de Cervantes.

Há um determinado parágrafo no artigo de Rodríguez que intriga o professor português, pois em primeiro lugar, o fragmento levanta a hipótese de que Cervantes possa ter escrito muito mais do seu Quixote do que foi efetivamente publicado e que esses escritos não foram divulgados porque foram censurados por seus editores, pela igreja e pelo estado, ou mesmo pelo próprio Cervantes. O fato de a segunda parte do Quixote ter sido publicada por Avellaneda em 1614 antes de Miguel de Cervantes e de o autor ter escrito sua obra levanta especulações críticas de que ele teria modificado seu texto em função do plagiador, comprovando, de alguma maneira, a questão posta por Rodríguez em seu artigo no conto de Viegas (2008).

Dentro desse aspecto, o plagiador Avellaneda pode ser considerado como um possível leitor, o qual interferiu, diretamente, na continuação das "aventuras do Cavaleiro da Triste Figura". Seu papel foi muito importante no modo como ele interpretou a primeira parte de Dom Quixote e criou a sua versão, embora esta fosse publicada antes da elaborada por seu autor original. Reguera (1997, p. 137) tratará de Avellaneda em seu livro, restringindo-se à gênese da obra de Cervantes. Não enfoca temas e nem instaura discussões a serem tratadas pela Estética da Recepção, embora o reconheça, já no título "La influencia 
de Avellaneda en el Quijote de 1615”, como um elo da recepção (como leitor de 1605) e da modificação da própria escrita de Cervantes.

Sublinhe-se o fato de Reguera (1997, p. 138) citar vários estudiosos que perceberam a sua influência na segunda parte de Dom Quixote. Menéndez Pidal afirma que a análise operada em torno disso não serve para descobrir "quem plagiou quem" mas "como cada autor se apoderó de matérias encontradas en la obra del outro y las utilizó para sus próprios propósitos, para construir con ellas su próprio 'argumento literário con que rebatir a su rival"'. Nesse sentido, a afirmação de Jorge Luís Borges sobre a leitura como um exercício de plágio e de recriação do texto sem mudar uma única linha do original também pode aplicar-se a ele.

Neste caso, as possíveis modificações que Cervantes fez, na segunda parte de seu texto, teriam sido motivadas por seu plagiador, aspecto que o conto de Viegas (2008) levanta. Ainda dentro da questão de Avellaneda, vale destacar que a sua identidade jamais foi conhecida, configurando-se como mais um enigma para a crítica literária. A nova condição do autor fictício árabe, posta a partir da segunda parte, seria uma reação de Cervantes para combater diretamente o plagiador e desqualificá-lo. De qualquer maneira, sua versão não chamaria a atenção, de acordo com Vieira (1998) se não fizesse plágio de Cervantes, pois não possui a mesma qualidade literária que a original. Em relação a este plágio, Vieira (1998, p. 42) destaca:

[...]se a intenção de Avellaneda era deturpar a imagem de Dom Quixote tal qual Cervantes teria deturpado a sua própria, o tiro saiu pela culatra, pois, apesar de todas as contrariedades que o Quixote apócrifo ocasionou, Cervantes soube transformar uma intriga pessoal num grande achado literário.

O próprio autor, não só transformou esse fato em situação constrangedora de plágio de sua obra, mas também a significou como um grande achado, como o próprio imitador, Avellaneda, não deixa de transparecer, com essa tentativa, sua admiração, como Reguera (2005, p.18) afirma: 
Se reescriben y desarrollan algunos de los episódios del primer Quijote dando lugar a un texto muy interesante en el que, con independencia de los propósitos que pudieran haber guiado al imitador, éste siguió en líneas generales la caracterización de los personajes y el planteamiento narrativo de las situaciones: la dependencia es constante, hasta en detalles mínimos, y muestra que Avellaneda, más allá de la crítica a Cervantes, había gustado de la novela de 1605, de manera que, en cierto sentido, también el Quijote apócrifo incorpora un cierto elemento de homenaje a Cervantes.

Isso significa que Avellaneda não agiu apenas como plagiador, mas também como leitor e admirador de Cervantes, tendo em vista que, de certa maneira, ele ajudou a compor a obra da segunda parte. No entanto, qual seria a influência significativa do Quixote de Avellaneda de 1614 para o de Cervantes de 1615? Entendemos pertinente essa questão, tendo em vista a leitura e critica centrada em pontos entendidos por ele como vulneráveis, na primeira parte do Quixote de Cervantes. Desse modo, ele parodia e critica os possíveis descuidos da obra, dentre esses descuidos, está o sumiço do cavalo de Sancho e depois a sua reaparição sem muita explicação e, também, o desacordo do nome de sua mulher entre a primeira parte e a segunda, de acordo com Reguera (1997). O crítico aponta uma série de intervenções que motivou em Cervantes fazê-las na sua segunda parte, inclusive em vários capítulos, contestando Avellaneda.

A crítica levanta muitas suspeitas sobre a identidade de Avellaneda. Há uma hipótese, segundo a qual Lope de Vega é o plagiador, pois o dramaturgo e Cervantes tinham suas diferenças literárias e de estilo, além de brigas pessoais. Também há outra afirmação a partir da qual se pode compreender que o plagiador pode ser um antigo companheiro da guerra de Lepanto Ginés de Pasamonte que, ao sentir-se contrariado pela representação como bandido que teve em Quixote, teria, supostamente, adotado a identidade de Avellaneda para plagiar a obra como uma reação.

Na segunda parte do Quixote, contudo, Reguera (1997) aponta que Cid Hamete, antes visto como um autor falso, passa a ter caráter de historiador, fato motivado por Avelhaneda. Dessa forma, já está instaurada na obra o mistério em torno da autoria e, em seu 
contexto específico, quem a plagiou, fato retomado por Borges e que novamente vem à tona no conto Manuscrito de Buenos Aires.

Estes elementos presentes no conto de Viegas, decorrem da interferência dos leitores de Cervantes, na reescritura e recriação de sua obra, instaurando uma discussão metalinguística em torno do fazer literário e do mistério instaurado em torno da autoria e da voz narrativa que já estavam no Quixote e são rediscutidos pelo autor do conto. O enredo da obra de Cervantes mostra como os diferentes narradores, o tradutor, o suposto autor e os leitores duques, da segunda parte de Dom Quixote, interferem na produção da história. Além disso, fatores extrínsecos, como o plágio da obra realizado por Avellaneda da sua segunda parte da obra está presente no prólogo.

Quanto ao enredo, a história possui, pelo menos, quatro narradores. De acordo com Reguera (1997, p. 157)

George Haley presenta un esquema muy útil y sencillo de los narradores que hay en el Quijote: Cervantes introduce también el recurso tópico de los autores ficticios como un elemento más de parodia de los libros de caballerías. Y Haley distingue los siguientes cuatro narradores en el Quijote: 1) "En primer lugar hay un "yo" anónimo que comienza la narración y que hace la presentación de don Quijote, para tener para cantar la palinoida al final del capítulo octavo, confesando su incapacidad para continuar la historia, dejando a don Quijote con la espada en el aire ya con sus fuentes se agotan en ese preciso instante." ; 2) "A éste le sigue un "segundo autor" que asume al "yo" y la narración con la descripción de la experiencia de lector insatisfecho con los ocho capítulos iniciales, que le habían dejado en ascuas, curioso por saber cómo acababa el episodio."; 3)Cervantes acude al recurso de un manuscrito encontrado en el Alcaná de Toledo. Necesita entonces un traductor. "Y es exactamente aquí donde hace su aparición el autor del manuscrito original: Cide Hamete Benengeli, moro y cronista primigenio de las altas hazañas de don Quijote". Éste nuevo autor es la la vez mago, poeta y historiador, y con él cambia la perspectiva de la novela: "de la búsqueda de fuentes se pasa por la tarea de la composición, y la história de la narración de Don Quijote se convierte esencialmente en la história de cómo narra Cide Hamete."; 4) "Queda un intermediario: el agente pasado por alto por aquellos que quieren identificar al segundo autor con Cervantes. El nebuloso personaje que cobra cuerpo al fin del capítulo VIII, para hilvanar el fragmento del primer autor con la aportación 
del segundo, y que reaparece en el capítulo final de la primera parte para hacer las últimas observaciones."

O primeiro narrador (e suposto autor) é o que começa a narrativa, questionado pelo segundo, que aparece logo no capítulo IX, dizendo: "Pareciome cosa imposible y fuera de toda buena costumbre que a tan buen caballero le hubiese faltado algún sábio que tomara a cargo de escribir sus nunca vistas hazañas, cosa que no faltó a ninguno de los caballeros andantes” (CERVANTES, edição 2005, p.84). Este não é o escritor original, pois parece ser mais um leitor crítico, que leu os oito primeiros capítulos e ficou insatisfeito e que por isso, assume a narrativa a partir desse momento. Isso significa que, até esse capítulo, não havia um autor original para as aventuras do protagonista, pois se espera que ele tenha elaborado toda a história e não tivesse dúvidas de como continuá-la, como demonstrou o primeiro. Por outro lado, o segundo também não se daria o trabalho de questionar a sua própria obra.

A dúvida que paira nessa abordagem, ao longo do livro de Cervantes, é sobre quem é o verdadeiro autor, bem como a identidade do narrador (ou narradores). Ao mesmo tempo, todos eles são leitores, pois um critica a capacidade do outro de contar a história. Isso acontece, principalmente, entre o primeiro, o segundo e o último narrador, justamente pelo grau de conhecimento que tinham sobre a história. E ainda há a presença de um tradutor, pois o dito autor fictício verdadeiro, Cid Hamete Benengeli, escreve em árabe.

\section{Das considerações investigativas}

O mistério da autoria posto em Dom Quixote, bem como a narração múltipla, é o assunto central de Pierre Menard: escritor do Quixote, de Jorge Luís Borges. Desse modo, o autor do conto "Manuscrito de Buenos Aires" revisita o tema discutido por Cervantes e que novamente é revisitado por Borges, que é o da autoria e da desconfiança posta na palavra do narrador. O assunto é atualizado por Borges em seu conto, quando propõe o enigma da cópia literal de Dom Quixote, porém, de uma forma completamente diferente. 
Desse modo, a busca da autoria do manuscrito apócrifo que contenha a explicação da história de amor interpolada entre Cardênio, Luscinda. Dom Fernando e Doroteia se constitui no mote investigativo e policial que organiza toda a narrativa do conto.

Dentro dessa questão, o conto se constitui como uma narrativa policial contemporânea, não só por apresentar os elementos de mistério e suspense próprios desse gênero, mas pela discussão literária, a interdisciplinaridade e a cadeia de recepção existente entre as obras e sua criação estética, isto é, o próprio conto, o poeta fictício Evaristo Cárdenas, Jorge Luís Borges, Arturo Pérez e por fim, Miguel de Cervantes.

O mistério em torno disso reside na questão em torno da existência ou não de mais textos escritos por Cervantes e se essa especulação não passa de novos plagiadores, à maneira de Avellaneda, que tentam passar-se pelo autor. Esse mistério faz com que venham à tona questões como: por que esse manuscrito está envolto em tanto segredo? Cervantes teria sofrido a censura da Inquisição, embora o seu Quixote não tenha sido proibido de circular, como os romances de cavalaria? E o manuscrito de Buenos Aires? Teria sido tudo uma invenção do próprio Cárdenas para conseguir notoriedade para si ou realmente guarda uma relíquia do autor do Quixote? E, por fim, permanece envolta em mistério a interpretação do personagem Rodríguez. A afirmação de que a obra seria limitada somente ao que foi escrito propõe que havia algo mais a se descobrir e que, por alguma razão, deveria permanecer secreto o seu conteúdo.

À maneira de um romance policial, o conto revitaliza o mistério da autoria posta por Cervantes, em Quixote, relaciona vários sujeitos (Borges, Cárdenas) a Cervantes e deixa esse enigma inacabado. O leitor termina o conto sem saber, de fato, se ao manuscrito é de autoria do autor do Quixote ou não, mesmo com a afirmação de que fora Cárdenas quem planejou tudo. Será mesmo?

\section{“MANUSCRITO DE BUENOS AIRES”, BY FRANCISCO JOSÉ VIEGAS: A LITERARY INVESTIGATION}

ABSTRACT: This article focuses on the analysis of the short story "Manuscrito de Buenos Aires" (2008), by Francisco José Viegas, considering the elements belonging to the detective genre and the 
contemporary fiction that can be verified in the narrative construction. The recurrence of such traits is characteristic of the work of Viegas, for whom "all literature is detective-like". In this sense, the featured short story is marked not only by detective-like elements, such as the detective character, the disappearance of an object (manuscript) and the search to unravel an enigma, but also by elements that are prominent in the contemporary narrative, such as the intertextuality and the reference to literature itself. The narrative, thus, becomes a compliment, especially to the work of Jorge Luis Borges and Miguel de Cervantes, and to an investigation that has literature as an object of obsession.

KEYWORDS: Francisco José Viegas; Detective gender; Contemporary narrative.

\section{REFERÊNCIAS}

BORGES, Jorge Luis. O conto policial. In: - Borges oral \& Sete noites. São Paulo: Cia das Letras, 2011. p.51-65

REGUERA, José Montero. El Quijote y la crítica contemporánea. Centro de Estudios Cervantinos, Alcalá de Henares: 1997.

. El Quijote durante cuatro siglos: lecturas y lectores. Valladolid, Universidad de Valladolid, Secretariado de Publicaciones e Intercámbio Editorial, 2005

VIEIRA, Maria Augusta da Costa. O dito pelo não dito: os paradoxos de Dom Quixote. EDUSP FAPESP, São Paulo: 1998.

VIEGAS, Francisco José. O manuscrito de Buenos Aires. SENA-LINO, Pedro (coord.) Contos policiais. Porto: Porto Editora, 2008. p.25-35.

Recebido em: 28/05/2018. Aprovado em: 16/07/2018. 